\title{
Artists' Pages: A Site for the Repetition and Extension of Conceptual Art
}

\section{Samantha Ismail-Epps}

To cite this article: Samantha Ismail-Epps (2016): Artists' Pages: A Site for the Repetition and Extension of Conceptual Art, Visual Resources, DOI: 10.1080/01973762.2016.1229350

To link to this article: http://dx.doi.org/10.1080/01973762.2016.1229350

曲 Published online: 06 Nov 2016.

Submit your article to this journal $\asymp$

Џ Article views: 33

Q View related articles $\asymp$

View Crossmark data $\nearrow$ 


\title{
Artists' Pages: A Site for the Repetition and Extension of Conceptual Art
}

\author{
Samantha Ismail-Epps
}

In the late 1960s, artists utilized documents such as floor plans, maps, instructions, correspondence, and photographs to record ideas or to take the place of artworks that need not be built. These documents were reproduced through the pages of inexpensive publications, intended to be accessible to wider, globalized audiences beyond the scope of physical exhibitions. This article argues that the page offers transformative qualities and functions as a medium for taking original, unique, and personal documents into the public domain; the page is repeatable, mass-produced, and puts art in the hands of the reader. Through using the pages that artists contributed to exhibition catalogs including Prospect 69, Konzeption/Conception, and July August September (all 1969), this article investigates the various ways in which artists adopted the medium of the page to extend the reach of their ideas and facilitate insights into their thinking and making processes. Working from the premise that artists were in the best position to explain their own work, the investigation conducts close readings of selected pages to discover the different functions of catalog contributions alongside, instead of, and after artworks were exhibited.

Keywords: Conceptual Art; Exhibition Catalogs; Artists' Pages; Documentation

Now that the exhibitions of early conceptual art are long gone and many of the works made to be impermanent, ${ }^{1}$ dismantled, or returned to stock, ${ }^{2}$ artists' ideas are most faithfully remembered in the pages of the exhibition catalogs that accompanied, supported, and on some occasions superseded the works on show. In the investigation that follows, I explore how the page was utilized and embraced as a medium for presenting and disseminating conceptual art. The page was a platform for direct access to artists' thought processes; it continues to perform this function for contemporary readers.

Documentation in the form of notes, plans, typed sheets of paper, correspondence, maps, sketches, photographs, and films was used by artists working in the early years of conceptual art to record and communicate ideas. ${ }^{3}$ The documents produced by artists working at the end of the 1960s lent themselves to reproduction in periodicals, newspapers, compendiums, and catalogs, partly due to their flat and inexpensive nature.

Media historian Lisa Gitelman, in Paper Knowledge (2014), points out that the essential role of a document is to teach or to show - to be accountable, to keep record, and to make information available. ${ }^{4}$ The proposals, instructions, and floor plans sent to exhibition organizers in the late 1960s serve this function. The documents provided 
staff with technical specifications and guidance to fabricate the pieces on an artist's behalf.

The exhibition Working Drawings and Other Visible Things on Paper Not Necessarily Meant to Be Viewed as Art (1966) organized by Mel Bochner (b. 1940) at the School of Visual Arts, New York, in December 1966 is a good illustration of the changes that occur when these informal pieces of paper are transformed into a "page." Bochner was interested in what was "upstream" of the work, and asked artists, writers, and musicians to submit their working drawings for display in the gallery. Due to financial limitations, it was not possible to frame and hang the drawings, so Bochner turned to the then-new technology of the Xerox machine to make copies that he could pushpin to the wall instead. ${ }^{5}$ Recalling this process, Bochner said:

But as they came out of the machine, these different sized and colored sheets were now all the same size and color, neatly stacked in the tray. Suddenly they were pages. In other words, they had already become a book ... ${ }^{6}$

The Xerox enabled Bochner to make multiple copies of the drawings that were then displayed in four ring binders presented on plinths (as sculptures would be) in the gallery setting. The exhibition, and in particular the use of Xerography in conceptual art, has been a feature of several academic and curatorial projects. ${ }^{7}$ Many of these have cited the influential work of Marshall McLuhan (1911-1980) and his assertion, "The message of print and of typography is primarily that of repeatability." However, of particular interest to this investigation is how Bochner recognizes the transformation of "documents" into "pages." When reproduced, the document is no longer the site of a private thought, or correspondence between artist and organizer; it is reproduced with the intention of reaching a far larger, and potentially unknown, audience. The original document ceases to be the only manifestation of the idea that it presents - the singular and original becomes a repeatable copy that circulates and preserves the ideas it contains. ${ }^{9}$ In the process, the document becomes inexpensive, non-precious, portable, repeatable, and public - and while the single, original document may possess some of these qualities, reproduction and presentation as a page confirm and intensify these. ${ }^{10}$

Artists and organizers began to investigate how pages could do more than solely present information about artworks. Towards the end of the 1960s, pages in exhibition catalogs and periodicals became considered viable sites for the production and presentation of artworks. These interests were most thoroughly explored by Seth Siegelaub (1941-2013), an exhibition organizer based in New York, who had already worked with artists including Carl Andre (b. 1935), Robert Barry (b. 1936), Douglas Huebler (1924-1997) and Lawrence Weiner (b. 1942). In December 1968, Siegelaub and Jack Wendler published Carl Andre, Robert Barry, Douglas Huebler, Joseph Kosuth, Sol LeWitt, Robert Morris, Lawrence Weiner (1968), known as the "Xerox Book," which made direct use of the Xerox machine in its production and presentation of artworks. ${ }^{11}$ In an important interview, "On Exhibitions and the World at Large," published in the December 1969 issue of the British periodical Studio International, Siegelaub made it 
clear that print was not only an acceptable medium, but the most appropriate medium for the presentation and dissemination of conceptual art:

But when art concerns itself with things not germane to physical presence its intrinsic (communicative) value is not altered by its presentation in printed media. The use of catalogues and books to communicate (and disseminate) art is the most neutral means to present the new art. The catalogue can now act as primary information for the exhibition, as opposed to secondary information about art in magazines, catalogues, etc., and in some cases the "exhibition" can be the "catalogue." 12

Siegelaub advocated a direct and "immediate" encounter with artists' works and ideas via the page, adding, "It just goes from mind to mind as directly as possible. The need for a community of critics to explain it seems obviously superfluous right now." ${ }^{13}$ Siegelaub demonstrated his views by producing a sequence of progressive exhibition catalogs from 1968 through to his departure from the New York art world in 1972, ${ }^{14}$ which omitted thematic titles and introductions, and provided artists with an open set of guidelines in which they could make and present their work. Projects included: One Month: March 1969 (1969), a calendar-exhibition where each artist was assigned a day, and July August September (1969). In May 1969, the British group Art and Language $^{15}$ published the first edition of Art-Language: The Journal of Conceptual Art. ${ }^{16}$ This began with the now often-cited "Introduction" asking whether an editorial in a periodical could "come up for the count" as work of conceptual art. Also included in the journal were "Sentences on Conceptual Art" (1969) by Sol LeWitt (19282007) and contributions by Dan Graham (b. 1942) and Lawrence Weiner. In the autumn of 1969, Lucy R. Lippard (b. 1937) curated 557,087 (1969), the first of her "numbers shows," 17 the accompanying catalogs of which consisted of loose index cards, while the catalog for Konzeption/Conception (1969) organized by Konrad Fischer (1939-1996) and Rolf Wedewer (1932-2010) contained the same material, "plans, concepts [and] fotos [sic]" as were presented in the exhibition. ${ }^{18}$

Due to the intentionally "accessible" nature of the catalogs mentioned, it was and continues to be possible for the reader/viewer to access artists' ideas via the page largely due to the straightforward presentation of visual and textual information. ${ }^{19}$ The role of critics as intermediaries also came under scrutiny since it was felt that artists were in the best position to explain their own work, ${ }^{20}$ if the work needed to be explained at all. By directly dealing with artists' pages in exhibition catalogs from the 1960s, it is possible to investigate the specific concerns that artists were addressing in relation to time, place, and context. This is not only intended to be in keeping with attitudes of the era, but also demonstrates how contemporary readers can use artists' pages in catalogs as direct links to the original conception and presentation of artworks and ideas. ${ }^{21}$

\section{Konzeption/Conception (1969)}

The catalog that accompanied the exhibition Konzeption/Conception (1969) organized by Konrad Fischer and Rolf Wedewer for the Städtisches Museum in Leverkusen, 
Germany from October 24 to November 23, 1969 makes for an interesting study of how artists utilized pages as platforms that were equal to presentation in a gallery. Each artist was given five pages in the catalog on which to present a project; this was to be the same as the work shown at the museum. According to press reviews of the time, visitors "had difficultly contending with the exhibition" presentation compared to the catalog, since it was felt that "concepts" in the form of sketches, descriptions, and plans were more coherently shown in the catalog form. ${ }^{22}$

\section{Hanne Darboven's Pages in Konzeption/Conception (1969)}

Hanne Darboven's (1941-2009) work consisted of notations upon the pages of textbooks, calendars, and diaries, in which she utilized printed lines and grids to arrange rows and columns of letters, numbers, and equations. Her work is best understood when viewed in its entirety, either as framed panels on a wall, or in books - supposedly her preferred method of presentation. ${ }^{23}$ Darboven's early pages, such as those in the catalog accompanying the seminal exhibition When Attitudes Become Form (1969), ${ }^{24}$ present only a fragment of these equations and are therefore difficult to follow. However, her five pages in the Konzeption/Conception (1969) exhibition catalog offer a more privileged perspective since the organizers conceived the catalog to present the same information as the exhibition itself (Figure 1).

Darboven begins the sequence with a handwritten statement explaining how the calculations (indicated using the letter "K") take the dates of the year 1969 as their point for departure. On the second page the calculations begin with the equation $17 \mathrm{k}=$ No. 1 , followed by a single sum. Darboven omits the plus and equals symbols from the handwritten columns of numbers that make up these sums, therefore requiring the reader to interpret the individual digits presented to arrive at a meaning for the calculation. Through this process, it becomes apparent that the sum comprises the first

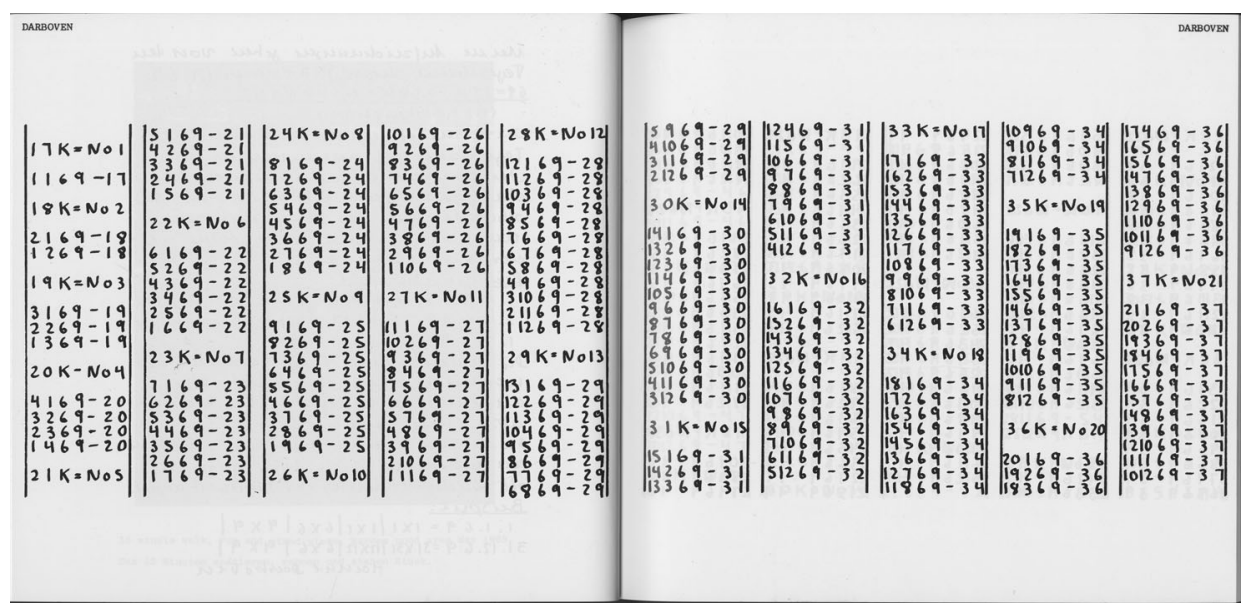

Figure 1 Hanne Darboven, artist's pages in Konzeption/Conception, exhibition catalog (Leverkusen: Städtisches Museum, 1969), n.p. Scan by Samantha Ismail-Epps. Image: (c) Hanne Darboven Foundation, Hamburg/VG BildKunst, Bonn 2016 and DACS 2016. 
day of the first month of the year 1969; $1+1+6+9=17 \mathrm{k}$. This is followed by a second statement: $18 \mathrm{k}=$ No. 2 , beneath which are two sums $2+1+6+9=18 \mathrm{k}$ and $2+1+6+$ $9=18 \mathrm{k}$; as the piece progresses, sequences accumulate into a dense mass of cross-sums of days, months, and numerals of the year 1969. The end of the piece is marked by a calculation using the digits of the last day of the year, $31+12+6+9=58 \mathrm{k}$; this is followed by a brief summary: $17 \mathrm{k}$ to $58 \mathrm{k}$ (the total sums of the digits used in the sequence of sums), No. 1-No. 42 (the amount of sets), 365 (the number of individual sums, and the number of days in one year) and 69 (the year of the work). ${ }^{25}$

To find clarity among the digits, the reader is required to spend time with the piece, perhaps by tracing columns with their forefinger, counting, adding, and scribbling notes as they would for a math equation in order to record the inner workings of Darboven's system. The logic of the piece does not reveal itself in one moment, but unfolds over time as individual elements are cross-referenced to demonstrate connections with each other. For Darboven, whether or not the reader understands the work is unimportant, for this work is about the experience of time - the time taken to write and the time taken to read. The format of the handheld catalog lends itself to this experience, allowing the reader to become absorbed in Darboven's activity within a private and intimate period of time. Darboven's presentation enables the reader to re-experience the artist's own thinking and making processes. Poised over the pages in a fashion like that of the artist, they retrace and relive Darboven's own actions to discover the meaning of her calculations for themselves.

\section{Jan Dibbets' Pages in Konzeption/Conception (1969)}

While Darboven's project was created specifically for the page, other artists chose to present documentation of previous projects in Konzeption/Conception (1969). Jan Dibbets' (b. 1941) pages included a reproduction of a postcard project developed with Seth Siegelaub, "On May 9 (Friday), May 12 (Monday) and May 30 (Friday) 1969 at 3:00 Greenwich Mean Time (9:00 EST) Jan Dibbets will make the gesture indicated on the overside at the place marked 'X' in Amsterdam, Holland," a typed statement dated April 25, 1969 certifying the triangular formation of cars, trains, and ships as a work of art and the reproduction of 19 photographic stills taken at Konrad Fischer's during the afternoon of June 9, 1969.

A double page is dedicated to the series of 19 photographic images made by Dibbets from the back of an enclosed, narrow space, looking outwards into the street through the glass doors which had turned a disused alley at Neubrückstrasse 12, Düsseldorf into Konrad Fischer's first exhibition space (Figure 2). Taken through the course of one afternoon, the images record the changing slant of shadows at 10minute intervals as the sun passes across the sky between 13:00 and 16:00 hours. This piece is one of a series of explorations by the artist in which the camera is used to document the passing of time over the course of one day, condensing this experience into a sequence of photographs presented as a line or a grid. ${ }^{26}$ There appears to be little difference between each frame here; the reader can only appreciate the sense of sequence upon viewing the full set of images. Sunlight bleeds into the narrow passage of Fischer's gallery, illuminating the street, cars, pedestrians, and daily routines of 


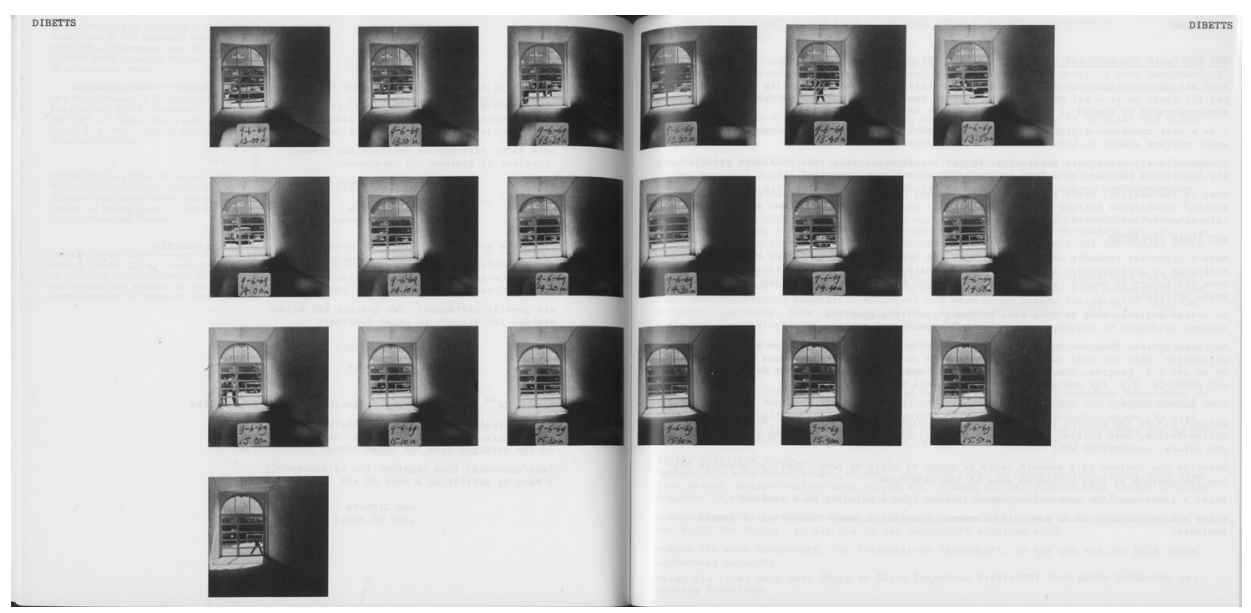

Figure 2 Jan Dibbets, The Shadows at Konrad Fischer Gallery, 1969 in Konzeption/Conception, exhibition catalog (Leverkusen: Städtisches Museum, 1969), n.p. Scan by Samantha Ismail-Epps. Image: (c) ARS, NY and DACS, London 2016.

the outside world. A sense of the everyday prevails throughout Dibbets' work; any person working in a given space (studio, office, domestic space $)^{27}$ for a period of an afternoon or a day will note how the windows in that space frame the changing strength and orientation of the sun, creating a natural marker of passing time.

The shadows cast by the mullions of the door and windows become most prominent at 15:30 hours. The arched top of the window is a prominent feature in each image and is reminiscent of the curved shape of the earth, or the daily path of the sun between dawn and dusk as captured by Dibbets' photographs. ${ }^{28}$ The curvature of the sun's path is better emphasized in Dibbets' drawing of the piece, submitted for the catalog 557,087 (1969). A large curve is drawn above the space to mimic the journey of the sun, arrows indicate the direction of travel, notations of time punctuate the line, and the point at which the shadow falls squarely into the gallery, indicated, as though it is anticipated, by bolder writing and the circling of 15:30 hours. This project, documented in both the drawing and the photographs, alludes to processes of navigation; universally, the sun can be used to tell the time, or to locate oneself within a landscape without the aid of modern technology. The method is trusted due to its regularity throughout past, present, and future days.

\section{July August September (1969)}

The exhibition July August September (1969) was not based in a gallery; instead organizer Seth Siegelaub invited 11 artists to submit proposals for artworks that would be accessible between July 1 and September 30, 1969. The catalog cover presented a map of the world and resulting projects took place in England, France, Germany, the Netherlands, Canada, the USA, and Mexico. Readers were provided with instructions in the form of maps, timetables, addresses, and telephone numbers at the back of the catalog to facilitate them in viewing the various projects. All text in the 
catalog was presented in English, French, and German translations, which was characteristic of Siegelaub's catalogs from 1969 onwards, reflecting his ambitions for a more international dissemination of artists' ideas. ${ }^{29}$

\section{Jan Dibbets' Pages in July August September (1969)}

In the "information" section of the catalog, Jan Dibbets described his project: "The work is a trip only to be traveled. All other specific information is contained within the work itself." 30 Dibbets' pages give the reader information that will enable them to carry out the trip described, suggesting in this statement that the work cannot be explained through these pages alone, but should be experienced.

When turning to Dibbets' pages in the main part of the catalog, the reader is first confronted with six photographs of the sea, the horizon line falling at different points in each image (Figure 3). ${ }^{31}$ It seems clear that these photographs have been taken at the same or similar site, with similar conditions, and possibly within the space of one day, since the sea remains relatively calm and the sky featureless in each. The images are uncaptioned, but numbered one to six, implying that they form part of some kind of sequence.

The following page reveals that these photographs were taken during a circular journey around the coast of the Netherlands, perhaps reminiscent of a holiday or hiking excursion. Dibbets provides a hand-drawn map and a typed schedule of the trip containing instructions for taking photographs at six sites along the route within a time frame of four days. The map drawn by Dibbets omits many geographical

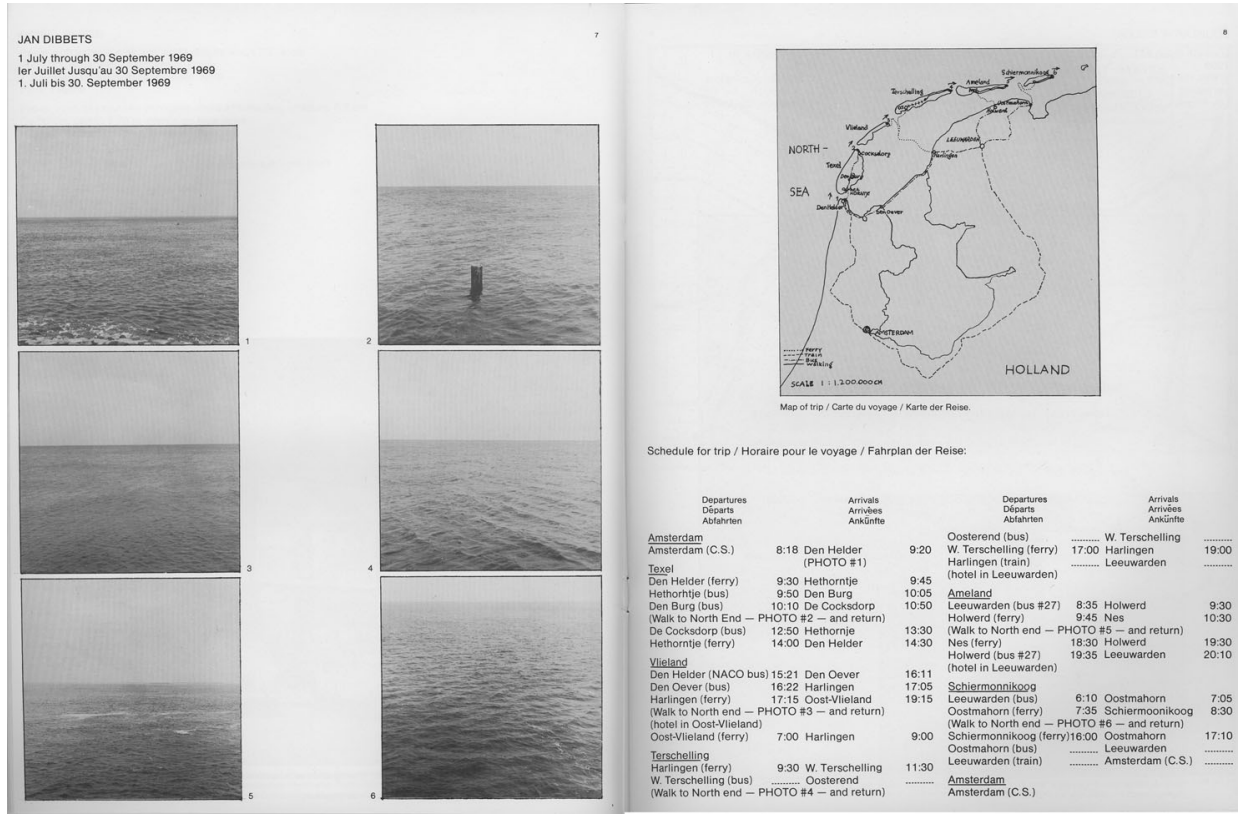

Figure 3 Jan Dibbets, 1 July through 30 September 1969 in July August September, exhibition catalog (New York: Seth Siegelaub, 1969), 7-8. Scan by Herbert Foundation, Ghent. Image: (c) ARS, NY and DACS, London 2016. 
details apart from outlines of the coast, place names, and four styles of hand-drawn line denoting different forms of travel across land and seascape - ferry, train, bus, and walking. This is a story map; it follows the route traveled from the perspective of an individual and gives only the information necessary to retrace this route in situ. Dibbets produced hand-drawn maps by tracing only the necessary details from geographical maps in his work often; this was demonstrated in the presentation of this project at the recent Seth Siegelaub: Beyond Conceptual Art exhibition at the Stedelijk Museum, Amsterdam ${ }^{32}$ alongside an artist book by Dibbets, Robin Redbreast's Territory: Sculpture 1969..$^{33}$ Both projects comprise segments of hand-drawn maps, simplified of geographical markers in favor of dotted lines to denote navigation across a designated space. Such maps would only translate practically for another individual traversing the same landscape. Otherwise the maps may be used to evoke the journey in the mind of the viewer, perhaps recalling Dibbets' journey, one of their own, or prompting the recollection of a similar memory.

Beneath the map is a detailed schedule for the four-day trip, identifying 19 points of transit. Place names, modes of transport, and precise times are listed as a timetable, inserted with instructions for taking the six photographs, first at Den Helder on the coast, and then at the northernmost end of each island crossed - Texel, Vlieland, Terschelling, Ameland, and Schiermonnikoog. Each photograph looks out towards the North Sea, staring ahead in the direction of travel. The photographs are too similar to each other to be considered useful in facilitating the proposed trip. Within them, the sea is vague and timeless in contrast to the minute-by-minute scheduling that announces them.

Both the artist and the reader can be active participants in the project; the pages document a journey already taken by Dibbets and invite the reader to follow in his path - in physical reality across the five Dutch islands, but also in their imagination. This contribution, like many others to the July August September (1969) catalog, seeks to explore the outdoor environment by taking artworks outside of the limits of institutions (in terms of physical buildings and logistical constraints). This exhibition catalog challenged the role of established galleries and museums and, in line with Siegelaub's interest to present art outside of centers such as New York, reached international audiences. ${ }^{34}$

\section{Richard Long's Pages in July August September (1969)}

Richard Long's (b. 1945) piece for the exhibition is titled Thee's Gotten Where Thee Cassn't Back'n Hassn't?, a colloquial West Country saying meaning "You've got it where you can't reverse it, haven't you?" The local dialect used by Long here resists translation in what is otherwise a tri-lingual catalog.

The site for Long's piece was the bed of the River Avon by Clifton Down, between the impressive Clifton Suspension Bridge (1864) and the dramatic landscape of Avon Gorge where the river runs along a limestone ridge. Brought up in nearby Bristol, the River Avon has been a reoccurring feature in walks, sculptures, and text-based works by the artist. Long's announcement card for his first solo exhibition held at Konrad Fischer's Neubrückstrasse gallery consisted of a commercially produced postcard depicting 
the gorge with the iconic bridge in the background. ${ }^{35}$ The card shows a young cyclist pausing for a moment during his journey to look at the suspension bridge. Long could be mistaken as the young man pictured, but it is another cyclist making a similar journey along a path well trodden throughout history and snapped for mass-produced mementos. Long rarely pictured himself in photographic documentation of his journeys. ${ }^{36}$ Instead, his photographs depict landscapes and the interventions he created using materials from the surrounding site including stones, rocks, twigs, and leaves arranged as lines and circles. Long creates these pieces and then looks on through the lens of the camera; in the print, he invites the viewer to do the same.

The photographs supplied by Long for the July August September (1969) catalog do not provide sufficient detail to identify the sculpture that he has positioned on the riverbank (Figure 4). The viewer is not given any further information and is therefore unsure of what they are looking for. Long had previously made sculptures that were indentations etched into sand, grass, or riverbanks; it is plausible that a similar piece has been made here which is not picked up by the lens of the camera, or that the piece had been eroded by the tide and natural elements. Due to the nature of the documentation used here, the viewer trusts that there is something on the bank to warrant the taking of these photographs and the excursion they are invited to undertake.

Long's photographs were taken from long range on the steep cliffs behind the A4 road, providing an aerial view of the site. The map on the second page also provides an aerial view, pinpointing the exact site of the sculpture on an Ordinance Survey (OS)

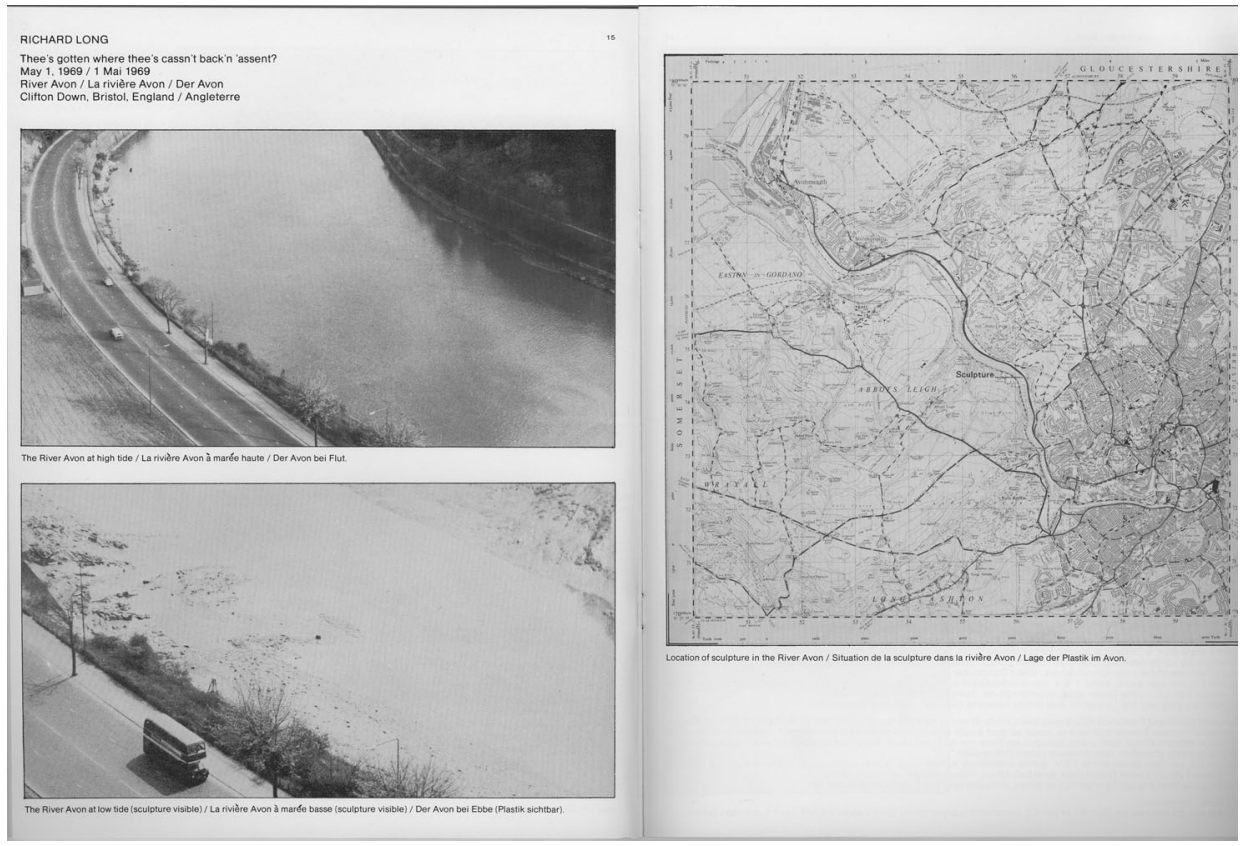

Figure 4 Richard Long, Thee's Gotten Where Thee Cassn't Back'n Hassn't? in July August September, exhibition catalog (New York: Seth Siegelaub, 1969), 15-16. Scan by Herbert Foundation, Ghent. Image: (C) Richard Long. All Rights Reserved, DACS 2016. 
map. The OS map provides a precise grid reference should the reader wish to locate the sculpture and make the journey personally. To accompany this information Long advises:

The sculpture can be seen 2 times each day at low tide. The exact time of the low tide can be gotten from a copy of "Bristol and Channel Ports Timetable, 1969", or a local newspaper "The Western Daily Press" (times quoted for either Avonmouth or Hotwells are suitable). ${ }^{37}$

Such specificity (of the text, but also the implied specificity of the photograph) suggests that Long wants the reader to make the effort to revisit this site. Given the specificity of the information provided by Long, today it is also possible to identify the precise location of the sculpture using technology such as Google Earth, but unlike monumental "earthworks" of his American contemporaries such as Walter De Maria (19352013), Michael Heizer (b. 1944), or Robert Smithson (1938-1973) this is to little avail in deciphering what Long's sculpture once was. Long's instructions and photographs provide the only lasting evidence of the sculpture, while also highlighting the limitations of using two-dimensional documentation to represent his physical, changeable, and ephemeral interventions into the landscape.

\section{Prospect 69 (1969)}

The second Prospect exhibition organized by Konrad Fischer and Hans Strelow for the Kunsthalle Düsseldorf was publicized as an "international preview of avant-garde art," taking place from September 30 to October 12, 1969. The catalog was produced as a newspaper and for the most part included advertisements from the represented galleries used to promote the artists they worked with and upcoming exhibitions. The catalog was printed in black and white on inexpensive newsprint, with the addition of red type on the front and back covers.

\section{Robert Barry's Pages in Prospect 69 (1969)}

Seth Siegelaub presented the artists Robert Barry, Douglas Huebler, Joseph Kosuth (b. 1945), and Lawrence Weiner in Prospect 69 (1969) by providing transcripts of self-conducted interviews in which the artists discussed the projects they had contributed to the exhibition. In response to the opening question asking what his piece was for the Prospect exhibition, Barry replies, "The piece consists of the ideas that people will have from reading this interview." 38 Barry explains how he uses language to "indicate the situation in which the art exists," adding, "The piece in its entirety is unknowable because it exists in the minds of so many people. Each person can really know only that part which is in his own mind." The short interview demonstrates how, for Barry, thoughts (including forgotten, unconscious and non-communicable thoughts) can constitute an artwork. In posing and answering his own questions, the artist recalls certain characteristics of the work, recording and preserving these in written language. 
The piece in Prospect 69 is in keeping with Barry's contributions to other exhibition catalogs in 1969, where he uses written language to capture and present a specific moment or thought, often fleeting in nature. Other works around this time include "Something I was once conscious of but have now forgotten ..." in Konzeption/Conception (1969) and "All the things I know but of which I am not at the moment thinking - 1:36pm, 15 June 1969. New York" in 557,087 (1969). In these works, the page is used as an interface between artist and reader, a place where the artist's momentary thought is captured and transmitted onwards.

\section{Daniel Buren's Pages in Prospect 69 (1969)}

Daniel Buren's (b. 1938) presence in the catalog consisted of a double page of alternating blue and white vertical stripes, like those pasted on the walls of Kunsthalle Düsseldorf during the exhibition. Both in the gallery and the catalog, the stripes were like the green and white stripes presented by Buren for Prospect 68 (1968). Due to the unbound nature of the catalog, the 1969 double page lent itself to being extracted, positioned, and retained according to the inclination of the reader. Since the work in the gallery space was destroyed after the exhibition, these pages are the only material remnants of Buren's work for Prospect 69.

Although some photographs exist of Buren's installation in Prospect $69,{ }^{39}$ these do not communicate the qualities of the work with the same immediacy as the catalog page. The photographs have been taken from a long range in order to capture the scale of the piece; they distance the viewer from the true color and materiality of the piece and differ from the experience of encountering the work through handling it in the catalog. Buren himself discounted photographs of his work as "souvenirs," stating in the Information (1970) exhibition catalog a year later, "The only possible information about my work is to really see it. Because every picture is an illusion / transformation / reduction. Any information on my work is just a deformation of it." ${ }^{40}$

Many of Buren's catalog pages produced around this time comprised $8.7 \mathrm{~cm}$ width stripes of white and color printed full-bleed across the page with little, if any, supplementary information. In an interview in Jef Cornelis's short untitled film made for Zoeklicht op de culturele actualiteit, Belgian Radio and Television in 1971, Georges Adé asked why Buren always repeated the same thing. The artist replied that it "is a way of showing that the exact same thing is completely different" in terms of the difference in time and also the "whole story around it is different, which I think changes things enormously." 41

\section{From Mind to Mind}

The assertion that conceptual artists working in the late 1960s used documents to record and present their work is not at all a new one. It was a topic of discussion and debate among artists and organizers working at a time when exhibitions contained more proposals, diagrams, sketches, statements, photographs, and correspondence than they did traditional art-objects. This led to some exhibitions, such as Konzeption/Conception (1969), being based on documentation entirely. But, as indicated by 
Douglas Huebler, "What did become of interest in the work ... was where it was located in relationship to the viewer" 42 and this is where the scope of the page becomes of interest.

The page has been able to occupy a unique position between artist and audience. Artists and organizers used the page to make ideas and artworks accessible and public, qualities that are essential to the wide dissemination of artworks during the late 1960s. Yet upon receivership, the page becomes an intimate space, one of private thought and internal dialogue.

McLuhan referred to media as "extensions of man."43 To extend is to stretch out, from artist to audience; the page bridges the gap. This outward extension is witnessed in Robert Barry's Prospect 69 interview and is referenced in Siegelaub's assertion that information "just goes from mind to mind as quickly and as directly as possible" along with Sol LeWitt's likening of an artwork to a "conductor from the artist's mind to the viewer's." ${ }^{4}$ Bonnie Mak, in How the Page Matters (2011), identifies the page as "the point of contact between author, design, text, image and reader," likening this network of relationships to an "interface." 45 Daniel Buren's pages in Prospect 69 operate clearly as an interface for the convergence of artist, artwork, audience, and exhibition site. Furthermore, Buren's pages in the Prospect 69 catalog have survived decades, enjoying greater longevity than the stripes pasted upon the walls of the Kunsthalle, which were destroyed at the end of the 13-day exhibition. Here the pages have been preserved within the catalog, a vehicle for distributing the work beyond the geographical boundary and time frame of the exhibition.

In addition to presenting and distributing information, the page also preserves what is printed upon it for future audiences. McLuhan affirmed that the purpose of documentation was to store and expedite information, which when gathered made it more accessible. ${ }^{46}$ This contrasts how artworks were made and exhibited in the late 1960s; many were ephemeral, installed in remote locations at the mercy of natural elements, or dismantled at the end of the exhibition - if they had been made at all. The specificity of the documents used by Dibbets and Long within the catalogs enables the artists' initial ideas to be preserved and retraced, both physically and imaginatively.

Through the page, the document is repeated, reproduced, and received; it has the potential of being revisited. Not coincidentally, these words all share the same prefix, "re," used to indicate time, denoting a "turning back" to an earlier moment. The notion of turning back manifests in the sequential nature of the catalogs. And while they do not all share a traditional codex binding, the definition of a publication alludes to a collection of separate leaves "bound" if not physically, then through shared material and conceptual qualities. Books, McLuhan states, were one of the first teaching aids (as well as the first mass-produced commodity), ${ }^{47}$ a function picked up by Gitelman in her description of documents having a "know / show" purpose. ${ }^{48}$ Publications facilitate the circulation of information due to their convenient size and form, mass-produced and inexpensive nature. The circularity of the connotations of "re" have been explored by Edgar Morin in the essay "RE: From Prefix to Paradigm," stating, "RE always includes a return to the past that resuscitates in the present. By this movement, RE catapults the past toward the future."49 
The page allows us to "turn back" to the moment when artworks of the late 1960s were first conceived and presented. It does so in a way that reflects attitudes of the era (democratic, immediate, accessible) and is not diluted through the passage of time or intermediacies since the page not only communicates, but also preserves.

Artists' pages have provided audiences, both of the late 1960s and today, with access to artists' thinking and making processes with immediacy and intimacy. Reproduction has safeguarded artists' ideas and artworks against the fate of being lost, damaged, or destroyed at the close of exhibitions. Daniel Buren's observation that repetition facilitates seeing the exact same thing as completely different is interesting in this respect. As the contents of the page remain the same, they exist in a format that lends itself to being taken into different contexts, where they are stored, shared, and revisited - and through which readers' interpretations may change or deepen with each subsequent encounter.

\section{Disclosure Statement}

No potential conflict of interest was reported by the author.

SAMANTHA ISMAIL-EPPS is a PhD candidate working at Norwich University of the Arts under the supervision of Prof. Lynda Morris. Her research examines how artists' pages contributed to exhibition catalogs and periodicals between 1966 and 1973 enable audiences to access ideas, attitudes, and artworks produced by conceptual artists working across Europe and the USA. Previous projects include participation in "Print and Production," a retreat hosted by Wysing Arts Centre, and a research Master Class at the Herbert Foundation, Ghent based around the exhibition "Accelerazione." Samantha has recently contributed a text to the catalog that accompanies the exhibition "Time Extended / 1964-1978: Works and Documents from the Herbert Foundation" (2016). She received both her BA (Hons) in Contemporary Textile Practice (2007) and MA in Textile Culture (2008) at Norwich University of the Arts. She teaches Art History and Contextual Studies at University of Suffolk and Great Yarmouth College.

1 Artworks that could be described as impermanent include: Richard Long, A Line Made by Walking, 1967; and Robert Barry, Inert Gas Series, 1969. See also Lawrence Weiner, "Statement of Intent," in January 5-31 1969, exhibition catalog (New York: Seth Siegelaub, 1969), n.p.

2 "Equivalent VIII was a reconstruction, not an original ... The original has been destroyed. At the time I made these pieces I did not have the money or the space to store the bricks so I had to return them to the brick supplier." Carl Andre, "Art and Value" (1978), in Carl Andre: Cuts, ed. James Meyer (Cambridge, MA: MIT Press, 2005), 47; Barbara Reise, “Untitled 1969': A Footnote on Art and Minimal Stylehood," Studio International 177, no. 910 (April 1969): 169.

3 Harald Szeemann, "About the Exhibition," in When Attitudes Become Form, ed. Harald Szeemann, exhibition catalog (Bern: Kunsthalle Bern, 1969); Lucy R. Lippard and John Chandler, "The Dematerialization of Art," Art International XII, no. 2 (February 1968): 31-6; Robert Pincus-Witten, “Anglo-American Standard Reference Works: 
Acute Conceptualism," Artforum 10, no. 2 (October 1971): 84; Ursula Meyer, Conceptual Art (New York: E.P. Dutton, 1972), xi-xiii.

4 Lisa Gitelman, Paper Knowledge: Towards a Media History of Documents (London and Durham, NC: Duke University Press, 2014), 1-2.

5 Mel Bochner and James Meyer, "Mel Bochner in Conversation with James Meyer," in Mel Bochner: Language 1966-2006, ed. Johanna Burton, exhibition catalog (Art Institute of Chicago; New Haven and London: Yale University Press, 2007), 135.

6 Ibid., 135.

7 Germano Celant and Lynda Morris, The Book as Artwork 1960-1972 (London: Nigel Greenwood, 1972); Benjamin H.D. Buchloh, "Conceptual Art 1962-1969: From the Aesthetic of Administration to the Critique of Institutions," October 55 (Winter 1990): 109; Alexander Alberro, Conceptual Art and the Politics of Publicity (Cambridge, MA: MIT Press, 2003), 130-151 (chapter: “The Xerox Degree of Art”); Charles Green, The Third Hand: Collaboration in Art from Conceptualism to Postmodernism (Minneapolis: University of Minnesota Press, 2001), 43-5 (chapter: "Conceptual Bureaucracy"); Hillel Schwartz, Culture of the Copy: Striking Likenesses, Unreasonable Facsimiles (New York: Zone Books, 1996); Xerography, curated by Michelle Cotton, Colchester: Firstsite, September 8-November 10, 2013.

8 Marshall McLuhan, Understanding Media: The Extensions of Man, rev. ed. (London: Routledge, 1994), 160.

9 "We are confronted here once more with that basic function of media - to store and expedite information. Plainly, to store is to expedite, since what is stored is more accessible than what has to be gathered." McLuhan, Understanding Media, 158.

10 "Reproduction is one clear way that documents are affirmed as such: one of the things people do with documents is copy them, whether they get published variously in editions, duplicated for reference, sort of or semi-published for internal circulation or proliferated online." Gitelman, Paper Knowledge, 1.

11 In the end, the "Xerox Book" was produced using off-set lithograph due to the expense and time it would had taken to print 1000 copies using Xerox technology. See Patricia Norvell, "Seth Siegelaub, April 17, 1969," in Recording Conceptual Art: Early Interviews with Barry, Huebler, Kaltenbach, LeWitt, Morris Oppenheim, Siegelaub, Smithson and Weiner by Patricia Norvell, ed. Alexander Alberro and Patricia Norvell (Berkeley: University of California Press, 2001), 35-9; "Seth Siegelaub," in A Brief History of Curating, ed. Hans Ulrich Obrist (Zurich: JRP Ringier, 2011) 121-2.

12 Seth Siegelaub and Charles Harrison, "On Exhibitions and the World at Large," Studio International 178, no. 917 (December 1969): 202.

13 Ibid., 203.

14 Sara Martinetti, "Chronology," in The Stuff that Matters: Textiles Collected by Seth Siegelaub for the Centre for Social Research on Old Textiles, exhibition catalog (London: Raven Row, 2012), 54.

15 Art and Language was a group founded in Coventry, England by Terry Atkinson, Michael Baldwin, David Bainbridge and Harold Hurrell. In 1970, art historian Charles Harrison and the artist Mel Ramsden became associated with the group and Joseph Kosuth joined as the American editor. Their collective work dates from 1967.

16 . Art-Language: The Journal of Conceptual Art 1, no. 1 (May 1969) included Sol LeWitt, "Sentences on Conceptual Art"; Dan Graham, "Poem-schema"; and Lawrence Weiner, "Statements." 
17 557,087, organized by Lucy R. Lippard, Seattle: Seattle Art Museum Pavilion, September 5-October 5, 1969 was followed by 995,000, Vancouver: Vancouver Art Gallery, January 13-February 8, 1970; 2,972,453, Buenos Aires: Centro de Arte y Comunicación (CAYC), December 4-23, 1970 and the touring exhibition $c$. 7,500, beginning at California Institute of the Arts, May 14-18, 1973 and traveling to nine further venues across the USA and UK in 1973 and 1974. The catalog for each venue consisted of a series of index cards presenting information, proposals, drawings, plans submitted by artists and a list of artists, general bibliography, and selected quotations.

18 More Konzeption Conception Now, ed. Stefanie Kreuzer, exhibition catalog (Leverkusen: Museum Morsbroich, 2015).

19 Some catalogs were given away for free, while others were distributed worldwide through the mail. Seth Siegelaub distributed independently produced catalogs and artists' books through his company International General; a price list from 1971 shows the majority of titles to be priced between $\$ 2$ and $\$ 5$, for example: January 5-31, 1969 (1969), \$2.50; 557,087/995,000 (1969/70), \$4.50; Robin Redbreast's Territo-

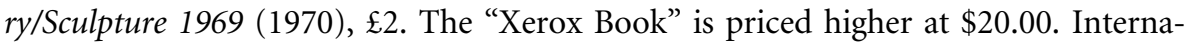
tional General, 1971 Booklist (New York, 1971), copy from Hugh Pilkington.

20 Sol LeWitt, "Paragraphs on Conceptual Art," Artforum 5, no. 10 (Summer 1967): 79.

21 "Conceptual artists take over the role of the critic in terms of framing their own propositions, ideas, and concepts. Because of the implied duality of perception and conception in earlier art, a middleman (critic) appeared useful. This [Conceptual] art both annexes the functions of the critic and makes the middleman unnecessary." Ursula Meyer, "Introduction," in Conceptual Art, viii.

22 "So it is not surprising that some critics seem to be perplexed by the installation on site and think they 'have not been in an exhibition at all', that they equate the catalog with the exhibition or even advise against a visit, since everything can be seen.” Kreuzer, More Konzeption Conception Now, n.p.

23 Lynne Cooke, "Open Work: Lynne Cooke on Hanne Darboven," Artforum International 47, no. 10 (Summer 2009): 57-8.

24 Hanne Darboven, in Szeemann, When Attitudes Become Form, n.p.

25 "The calendar is merely a vehicle, with no other meaning for the work, but by permutating its sequences of order through endless cross-sums and progressions, Darboven creates her own time ...." Lucy R. Lippard, "Hanne Darboven: Deep in Numbers," Artforum 8, no. 7 (October 1973): 35; catalog text by Johannes Cladders for Hanne Darboven, exhibition catalog (Mönchengladbach: Städtisches Museum, February 25-April 1, 1969), reproduced in Lucy R. Lippard, Six Years: The Dematerialization of the Art Object from 1966 to 1972 (Oakland: University of California Press, 1997), 77.

26 See also Jan Dibbets, “The Shadows in My Studio" (1969), discussed in Rudi Fuchs, "The Eye Framed and Filled with Color," in Jan Dibbets: Interior Light, ed. Rudi Fuchs (New York: Rizzoli, 1991), 10-12.

27 Around this period, Dibbets created similar works using photographs taken at 10minute intervals in various spaces, including Shortest Day at My House in Amsterdam (1970) and The Shortest Day of 1970 Photographed from Sunrise to Sunset, The Solomon R. Guggenheim Museum of New York (1970).

28 Dibbets continued to work with windows in the 1980s and 1990s: see Ten Windows (1988-97); Wayzata (1989-90).

29 Siegelaub and Harrison, "On Exhibitions and the World at Large," 202-3. 
30 July August September, ed. Seth Siegelaub, exhibition catalog (New York: Seth Siegelaub, 1969), 25.

31 Dibbets had worked with the sea tide previously when filming 12 Hours Tide Object, Correction of Perspective, Dutch Coast with Gerry Schum as part of the television exhibition LAND ART (1969). See Ulrike Groos, Ready to Shoot: Fernsehgalerie Gerry Schum videogalerie schum, exhibition catalog (Düsseldorf: Kunsthalle, 2004), 96-9.

32 Seth Siegelaub: Beyond Conceptual Art, curated by Leontine Coelewij and Sara Martinetti in collaboration with the Stichting Egress Foundation/Marja Bloem, Amsterdam. Stedelijk Museum, Amsterdam, December 12, 2015-April 17, 2016.

33 Jan Dibbets, Robin Redbreast's Territory: Sculpture 1969 (Cologne and New York: König/Seth Siegelaub, 1970).

34 Norvell, "Seth Siegelaub, April 17, 1969," 41.

35 Richard Long, Announcement Card (Düsseldorf: Galerie Konrad Fischer, 1968). Discussed in Andrew Wilson, "From Page to Page," in Heaven and Earth, ed. Clarrie Wallis (London: Tate Publishing, 2009), 195 and Lynda Morris, "Idea + Idea," in Time Extended/1964-1978. Works and Documents from the Herbert Foundation (Ghent: Herbert Foundation, 2016), 24-25.

36 With the exception of photographs depicting the artist in Prospect 69, ed. Konrad Fischer and Hans Strelow, exhibition catalog (Düsseldorf: Kunsthalle, 1969); VI. Guggenheim International Exhibition, ed. Diane Waldman, exhibition catalog (New York: Guggenheim Museum, 1971); Richard Long, "Richard Long Standing Near His Walk," Studio International 181, no. 933 (May 1971): 224.

37 Siegelaub, July August September, 25.

38 Robert Barry, untitled interview in Fischer and Strelow, Prospect 69, 26.

39 Daniel Buren, "Artwork: Papiers collés blanc et bleu," Daniel Buren Catalog Raisonné 1967-1972, http://catalogue.danielburen.com/artworks/view/2067.

40 Cited in Information, ed. Kynaston McShine, exhibition catalog (New York: Museum of Modern Art, 1970), 30.

41 Koen Brams, “Two Exhibition-Related Films by Jef Cornelis," Tate Papers 12 (Autumn 2009), http://www.tate.org.uk/research/publications/tate-papers/12/two-exhibitionrelated-films-by-jef-cornelis.

42 Patricia Norvell, "Douglas Huebler, July 25, 1969," in Alberro and Norvell, Recording Conceptual Art, 136.

43 McLuhan, Understanding Media, 7.

44 Sol LeWitt, "Sentences on Conceptual Art," 0-9 5 (January 1969): 3-5.

45 Bonnie Mak, How the Page Matters (Toronto, Buffalo and London: University of Toronto Press, 2011), 32.

46 McLuhan, Understanding Media, 158.

47 Ibid., 174.

48 Gitelman, Paper Knowledge, 1.

49 Edgar Morin, "RE: From Prefix to Paradigm," World Futures 61, no. 4 (June 2005): 254-67 